\title{
Hysterectomy costs depending on operational technique
}

\author{
Ewa Kala ${ }^{1}$, Rafal Stojko ${ }^{1,2}$, Marcin Sadlocha ${ }^{1,2}$ \\ ${ }^{1}$ Department of Obstetrics and Gynecology with Gynecological Oncology Subdivision, \\ Brothers Hospitallers of Saint John of God Hospital, Katowice, Poland \\ ${ }^{2}$ The Chair of Woman's Health, The Medical University of Silesia in Katowice, Poland
}

\begin{abstract}
Objectives: The aim of the study was to perform a comparative analysis of hysterectomy costs versus the operative technique based on the data of 656 patients operated at the Department of Obstetrics and Gynecology with Gynecological Oncology Subdivision, Brothers Hospitallers of Saint John of God Hospital, Katowice, between 2016 and 2018 (until May 31, 2018).

Material and methods: This retrospective research involved 656 patients who underwent hysterectomy for non-oncological reasons. The patients were subdivided into three groups, depending on the operative method (transabdominal, laparoscopic or transvaginal). Next, treatment costs were compared, including the costs of hospitalization, operating block, operating block materials, drugs, anesthesia, and medical staff. The duration of the operation and the hospital stay were also analyzed as they significantly affected the final result.

Results: Data analysis revealed that transvaginal hysterectomy generated the lowest costs. A positive relationship between low costs and the duration of surgery and hospitalization, which is significantly shortened in case of transvaginal hysterectomy, was confirmed.

Conclusions:

1. The transvaginal approach is the most cost-effective technique of hysterectomy.

2. Apart from the financial advantage, transvaginal hysterectomy is also associated with shorter hospitalization and faster recovery.

3. Emphasis should be placed on training physicians in minimally invasive hysterectomies - especially the transvaginal approach — so that the greatest percentage of patients who are deemed eligible for hysterectomy could be operated using this minimally invasive technique.
\end{abstract}

Key words: hysterectomy; operation; costs

Ginekologia Polska 2018; 89, 12: 672-676

\section{INTRODUCTION}

Hysterectomy is one of the most common gynecological procedures, both in women of childbearing age (immediately after cesarean section) and during the perimenopausal period. The most common non-oncological indications for hysterectomy include symptomatic uterine myomas, abnormal bleeding from the genital tract, endometriosis, and prolapse of the reproductive organs [1, 2]. Several surgical techniques to remove the uterus are currently available, depending on the indications for surgery and uterine size, mobility and shape, as well as operator experience, or patient preferences. These include: abdominal hysterectomy
(TAH) or supracervical hysterectomy (TASH); total laparoscopic hysterectomy (TLH); laparoscopic-assisted vaginal hysterectomy (LAVH); laparoscopic supracervical hysterectomy (LASH), and transvaginal hysterectomy (TVH). Transvaginal or laparoscopic removal of the uterus is referred to as 'minimally invasive' because it is not associated with the formation of a large wound in the abdominal wall. Usually, minimally invasive procedures result in a shorter period of hospitalization and convalescence, which significantly lowers the overall cost [3-5]. In an increasingly technologically advanced medicine this is an important advantage. Methods which combine effectiveness with minimal financial burden 
for the healthcare facilities are the most desirable [6, 7]. Data from various centers around the world show that the frequency of using a particular technique varies, depending primarily on operator experience and their training. In Poland, according to data from the NFZ (National Health Fund), 30118 hysterectomies were performed in 2016 alone, including 27088 (90\%) - transabdominal, 2019 (6.5\%) - LASH/TLH, and 1011 (3.5\%) transvaginal. This means that most centers choose the transabdominal technique as their method of choice $[5,8]$. At the Department of Obstetrics and Gynecology with the Subdivision of Oncological Gynecology, Brothers Hospitallers of Saint John of God in Katowice, the number of transabdominal hysterectomies in the last few years has significantly decreased in favor of transvaginal surgery (Fig. 1-2).

\section{Objectives}

The aim of the study was to compare the costs of hysterectomy for non-oncological reasons, depending on the surgical technique. The study included patients hospitalized at the Department of Obstetrics and Gynecology with the Subdivision of Oncological Gynecology, Brothers Hospitallers of Saint John of God Hospital in Katowice in 2016-2018 (the number of procedures performed until May 31, 2018) and operated for non-oncological reasons.

\section{MATERIAL AND METHODS}

This retrospective study included 656 patients who had their uterus removed due to non-cancerous causes. The patients who were initially operated for reasons other than cancer but whose histopathological result indicated a malignancy were not taken into account. Uterine myomas were the most common indication for hysterectomy (45\%), followed by atypical hyperplasia of the endometrium (15\%), abnormal bleeding from the genital tract (13\%) and, to a much lesser extent, dysplasia of the cervix or changes in the appendages. A similar percentage distribution of indications for surgery was characteristic for particular types of surgery. The patients were subdivided into three groups, depending on the surgical method: transabdominal technique (TAH and TASH), transvaginal (TVH), and laparoscopic ( $L A V H$, TLH and LASH). The reason why laparoscopic surgeries have been qualified to one group is lack of statistically significant differences in procedure duration at our Department. In fact, the LAVH procedures should be included in a separate group, but in our case only 7 (out of the total number of laparoscopic procedures - 165) LAVH surgeries were performed during the study period. Thus, their significance was marginal. There were hardly any differences in the range of equipment. Video paths, monopolar (monopolar hooks) and bipolar (BiClamp and BiSect) electrocoagulation tools, and morcellators were used both, for LASH and TLH. The

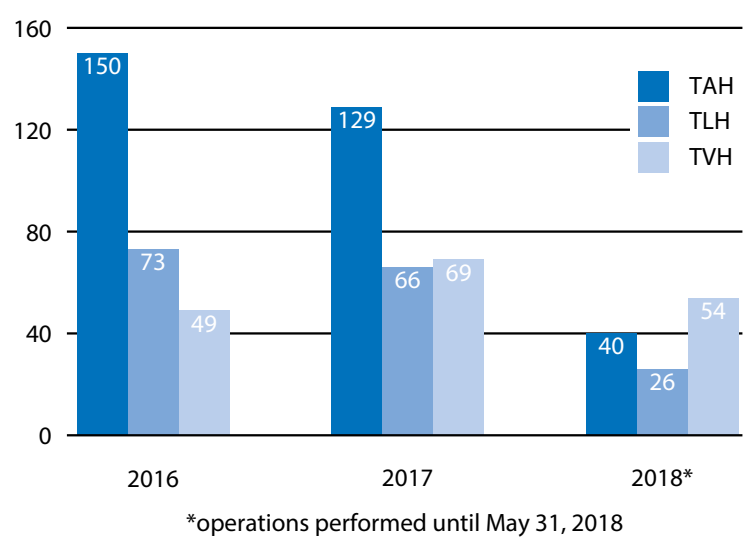

Figure 1. Number of hysterectomies depending on operational technique

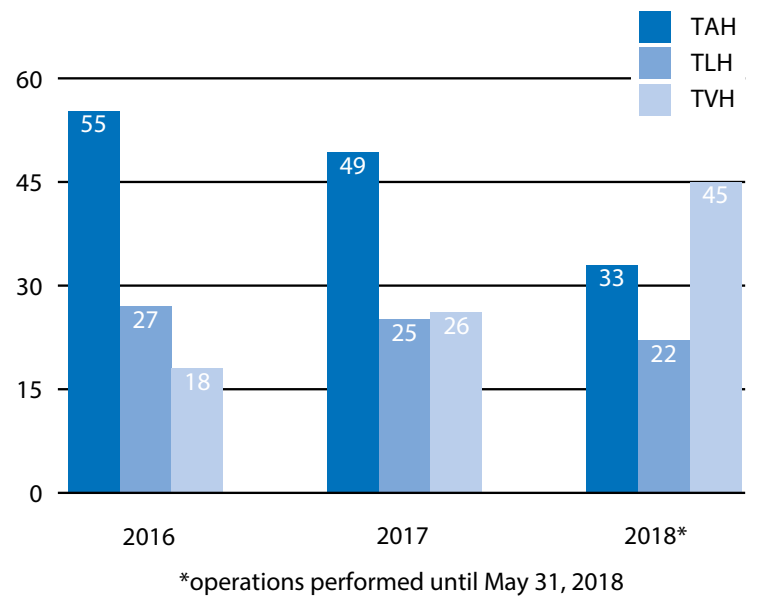

Figure 2. Number of hysterectomies depending on operational technique [\%]

uterine body was dissected using monopolar electrocautery (no loop was used), then morcellated and removed. Monopolar and bipolar electrocautery (BiClamp) were used for laparotomy. Transvaginal operations were performed with the help of LigaSure or BiClamp tools and monopolar electrocautery. Almost half of the patients were operated using the LigaSure closing system. LigaSure is a disposable equipment, other equipment is reusable. A comparison of the homogeneous - in terms of the duration of the surgery, equipment used, length of ward stay or drug consumption - group of the abdominal operations (TASH and $\mathrm{TAH}$ ) and the equally homogeneous group of laparoscopic procedures (LASH, LAVH and TLH) seems to be the most suitable way of approaching the issue. No statistically significant differences were found in terms of age, weight, previous surgical procedures or comorbidities between the individual groups of patients. The analysis of the hospital treatment costs included the cost of the following: a) op- 
erating block materials, i.e. everything which is registered by the hospital pharmacy and issued 'per patient', e.g. surgical drapes (includes the LigaSure cost); b) the operating block, i.e. all fixed costs calculated per operating block hour, e.g. maintenance of premises, equipment depreciation, service, small household, office materials (does not include staff remuneration costs); c) medicines; d) anesthesia; e) personnel; f) patient stay, i.e. all fixed costs related to the functioning of the ward, e.g. equipment depreciation, midwife salaries, a part of physician salaries, some medicines, readiness of the operational block and anesthesiology department, technical maintenance, cleaning, administration. The cost of the complication treatment also was included into our analysis. Complications in each of the subgroups included: a) laparotomies - revision of the postoperative wound; repair of a damaged bladder - done during the same stay; 2 units of Packed Red Blood Cells had to be transfused twice; b) laparoscopies — one relaparotomy due to internal bleeding on the same day as the primary operation and a transfusion of 3 units of Packed Red Blood Cells and 2 units of Fresh Frozen Plasma; one relaparotomy due to internal bleeding on the same day as the primary operation and a one transfusion of 2 units of Packed Red Blood (ells; c) transvaginal operations - one relaparotomy due to internal bleeding performed 2 days after the primary operation and a transfusion of 3 units of Packed Red Blood Cells; one transfusion of 2 units of Packed Red Blood Cells; one abscess in the vagina - puncture two weeks after the primary operation. Duration of surgery and of hospital stay were also included in the statistical analysis. Mean total hospital stay was: TAH -6.6 days; TLH -4.9 days; TVH -4.5 days. All these costs summed together provide the total cost of hospital treatment per patient. Basic statistical tools of the Statistica 8.0 PL program were used for the calculations.

\section{RESULTS}

Mean cost of medications per patient was the lowest for the transvaginal surgery and amounted to 66 PLN (Polish currency), followed by 123 PLN and 149 PLN for transabdominal and laparoscopic surgeries, respectively. Mean cost of the operating block was also the lowest for the transvaginal surgery - $133 \mathrm{PLN} /$ patient, while the largest costs were generated by laparoscopic procedures - $303 \mathrm{PLN} /$ patient. Laparotomies produced block costs of $190 \mathrm{PLN} /$ patient. The financial distribution was similar in case of anesthesia and personnel costs - the lowest for transvaginal and the highest for laparoscopic approaches. Differences between transvaginal and laparoscopic techniques were approximately 30\% (cost of anesthesia) and 40\% (personnel cost), respectively. Only the costs of the operating block materials were the highest for transvaginal surgery, but only those performed with LigaSure. The costs of hospital stay were the smallest for transvaginal surgery - 1895 PLN/patient, slightly larger for laparoscopic surgery - 1955 PLN/patient and the largest for the abdominal surgeries - 2901 PLN/patient. They resulted-among others - from the length of the stay in the ward - on average 4.5 days for transvaginal hysterectomies, 4.9 days for laparoscopies, and 6.6 for laparotomies. The total mean cost of hospital treatment was the smallest in case of transvaginal surgery and amounted to 2764 PLN/patient, which is $25 \%$ less than the cost of a laparoscopic surgery, (3345 PLN/patient), and 30\% less than transabdominal procedures (3792 PLN/patient) (Fig. 3-9).

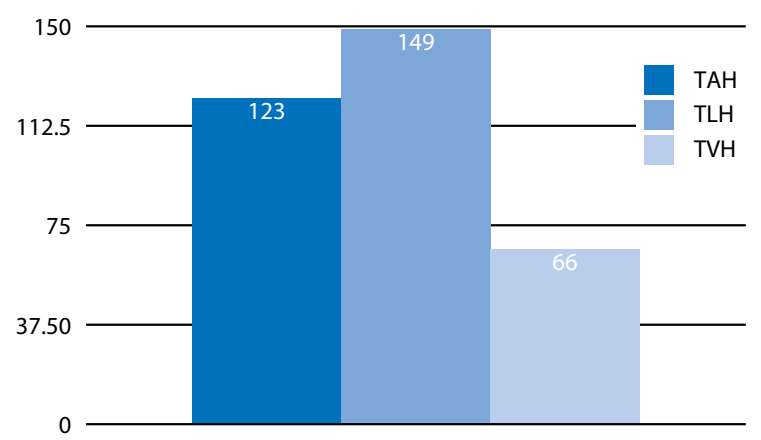

Figure 3. Drug costs [PLN — Polish currency]

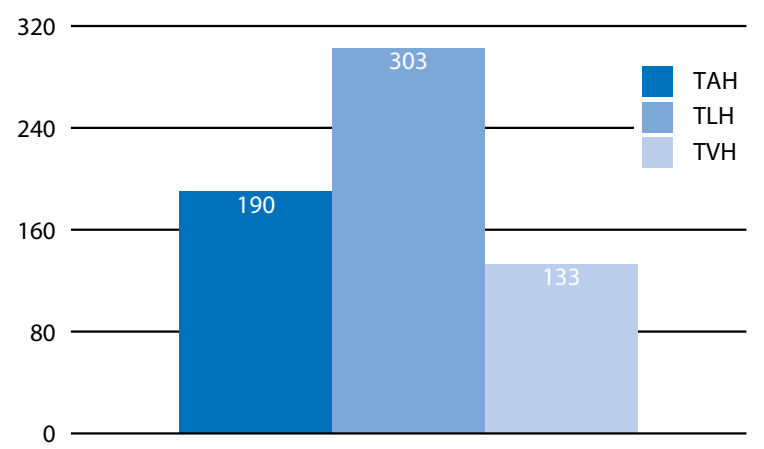

Figure 4. Operating block costs [PLN - Polish currency]

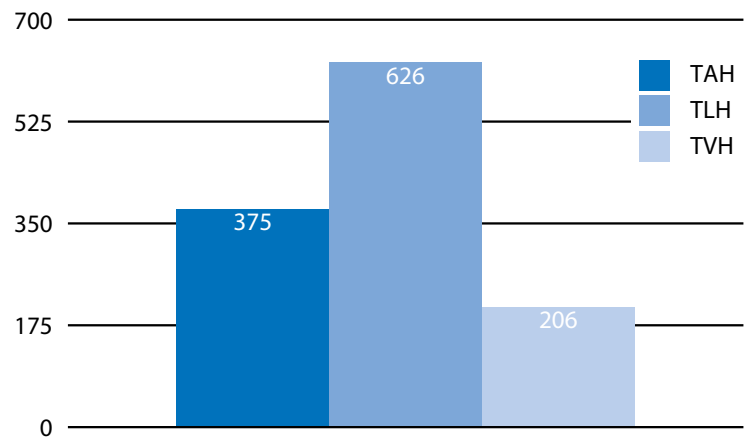

Figure 5. Anesthesia costs [PLN - Polish currency] 


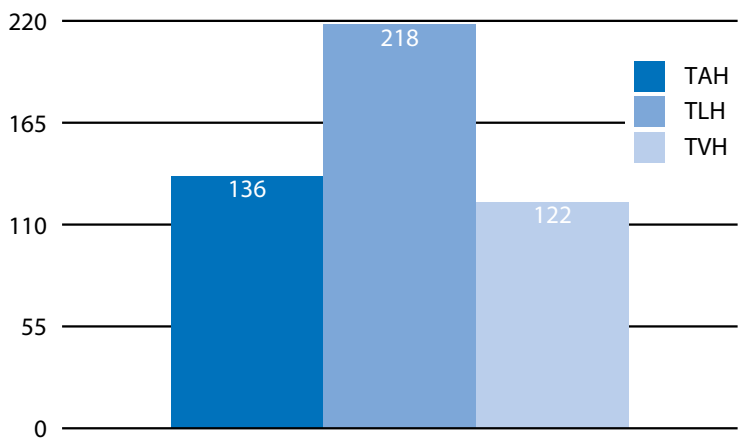

Figure 6. Medical staff costs [PLN - Polish currency]

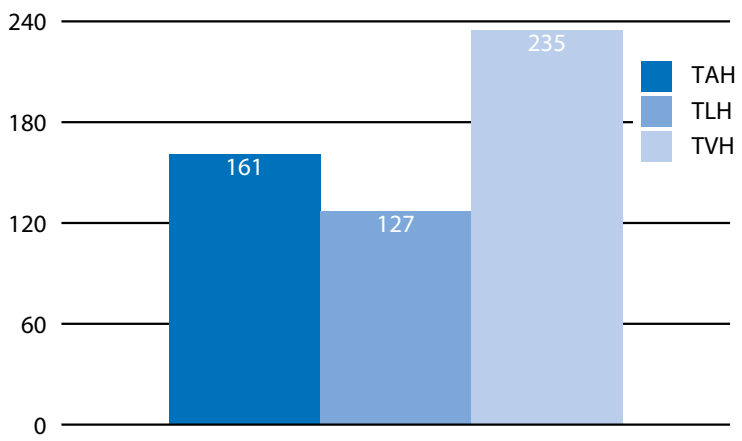

Figure 7. Costs of operating block materials [PLN - Polish currency]

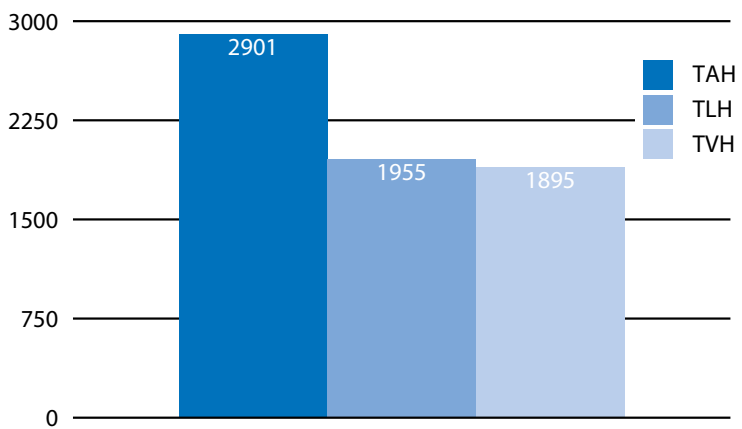

Figure 8. Costs of hospital stay [PLN — Polish currency]

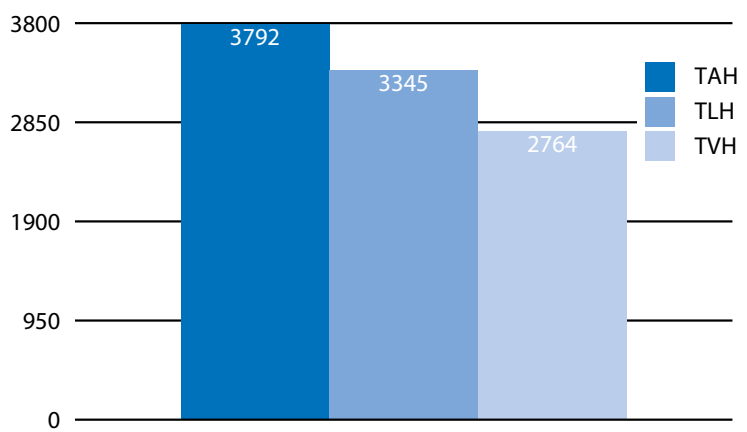

Figure 9. Total costs of hospitalization per patient [PLN — Polish currency]

\section{DISCUSSION}

Hysterectomy is the second most frequently performed gynecological operation after cesarean section. Our study showed that transvaginal surgery is the most economically effective approach to hysterectomy, which is consistent with reports all around the world. An overview of Cochrane Database 2009 [9] proves that it is not only the least expensive, but also the safest method of removing the uterus, if there are no medical contraindications. According to ACOG (The American College of Obstetricians and Gynecologists), vaginal hysterectomy should be the method of choice, if possible, as it is associated with better therapeutic results compared to other surgical techniques. [1] Aarts et al., came to similar conclusions in the 2015 Cochrane review - in the studies which were considered, transvaginal hysterectomy should be the method of choice because it allows the patient to return to daily functioning more quickly owing to a shorter time of surgery and hospital stay. Thus, it requires the least financial outlay [10]. Warren L et al., compared the costs of minimally invasive hysterectomy (mini-laparoscopic and transvaginal) with laparotomy. They obtained significantly better results, both in treatment results and in the costs, in the case of minimally invasive techniques, especially the transvaginal ones [11]. Kelly N. Wright et al., reached similar conclusions, pointing out that minimally invasive techniques should be sought, minimizing the costs and improving treatment outcomes [12]. Transvaginal removal of the uterus is the most cost-effective in comparison to other techniques, while the costs of laparoscopy and laparotomy are similar. It is associated with a greater financial outlay on laparoscopy equipment, although the length of stay in the ward and return to full efficiency is shorter in case of laparoscopy [13, 14], which is consistent with the findings of Augusto KL et al., who conducted a cohort study in Brazil between 2010 and 2014. The costs of laparotomy are the highest, yet it is still the most frequently chosen method of removing the uterus [15]. Operator experience is, of course, an important aspect of the surgical procedures. As presented in a study by Boyd et al., gynecologists who performed more than 10 hysterectomies per year had significantly better operational outcomes (lower mortality and fewer postoperative complications) as compared to doctors who performed fewer than 10 hysterectomies per year. In addition, they were more likely to develop in minimally invasive surgery [16]. Wright et al., reached similar conclusions by analyzing transabdominal hysterectomies performed in patients due to endometrial cancer [17]. Similarly, Rogo-Gupta et al., who analyzed vaginal hysterectomies, reported that greater operating experience is associated not only with better prognosis but also better financial effect of the surgical treatment [18]. An additional factor which shortens the operation time is the use of the latest and most advanced 
operating equipment, including cutting tools with electrocoagulation, which was observed during the analysis of data from our Department.

\section{CONCLUSIONS}

1. The transvaginal technique is the most cost-effective method of hysterectomy.

2. Apart from the financial benefits, transvaginal hysterectomy is also associated with shorter hospitalization and recovery period.

3. Emphasis should be placed on training physicians in minimally invasive hysterectomies - especially the transvaginal approach - so that the greatest percentage of patients who are deemed eligible for hysterectomy could be operated using this minimally invasive technique.

\section{REFERENCES}

1. Committee Opinion No. 701. The route of hysterectomy for benign disease. American College of Obstetricians and Gynecologists. Obstet Gynecol. 2017; 129: e155-9.

2. Chopin N, Malaret JM, Lafay-Pillet MC, et al. Total laparoscopic hysterectomy for benign uterine pathologies: obesity does not increase the risk of complications. Hum Reprod. 2009; 24(12): 3057-3062, doi: 10.1093/humrep/dep348, indexed in Pubmed: 19801572.

3. Tohic ALe, Dhainaut C, Yazbeck C, et al. Hysterectomy for benign uterine pathology among women without previous vaginal delivery. Obstet Gynecol. 2008; 111(4): 829-837, doi: 10.1097/AOG.0b013e3181656a25, indexed in Pubmed: 18378741.

4. David-Montefiore E, Rouzier R, Chapron C, et al. Collegiale d'Obstétrique et Gynécologie de Paris-lle de France. Surgical routes and complications of hysterectomy for benign disorders: a prospective observational study in French university hospitals. Hum Reprod. 2007; 22(1): 260-265, doi: 10.1093/humrep/del336, indexed in Pubmed: 16950826.

5. Malinowski A, Makowska J, Antosiak B. Całkowite laparoskopowe usunięcie macicy - wskazania i powikłania u 158 pacjentek. Ginekol Pol. 2013; 84(4): 252-257.

6. Dayaratna S, Goldberg J, Harrington C, et al. Hospital costs of total vaginal hysterectomy compared with other minimally invasive hysterectomy.
Am J Obstet Gynecol. 2014; 210(2): 120.e1-120.e6, doi: 10.1016/j. ajog.2013.09.028, indexed in Pubmed: 24060444.

7. Pynnä K, Vuorela P, Lodenius $L$, et al. Cost-effectiveness of hysterectomy for benign gynecological conditions: a systematic review. Acta Obstet Gynecol Scand. 2014; 93(3): 225-232, doi: 10.1111/aogs.12299, indexed in Pubmed: 24180560.

8. Stadnicka G, Iwanowicz-Palus G, Mazurek A, et al. Poczucie satysfakcji z życia pacjentek po histerektomii. Ginekol Pol. 2012; 83: 347-352.

9. Nieboer T, Johnson N, Lethaby A, et al. Surgical approach to hysterectomy for benign gynaecological disease. Cochrane Database of Systematic Reviews. 2009, doi: 10.1002/14651858.cd003677.pub4.

10. Aarts JWM, Nieboer TE, Johnson N, et al. Surgical approach to hysterectomy for benign gynaecological disease. Cochrane Database Syst Rev. 2015(8): CD003677, doi: 10.1002/14651858.CD003677.pub5, indexed in Pubmed: 26264829.

11. Warren L, Ladapo JA, Borah BJ, et al. Open abdominal versus laparoscopic and vaginal hysterectomy: analysis of a large United States payer measuring quality and cost of care. J Minim Invasive Gynecol. 2009; 16(5): 581-588, doi: 10.1016/j.jmig.2009.06.018, indexed in Pubmed: 19835801.

12. Wright $\mathrm{KN}$, Jonsdottir $\mathrm{GM}$, Jorgensen $\mathrm{S}$, et al. Costs and outcomes of abdominal, vaginal, laparoscopic and robotic hysterectomies. JSLS. 2012; 16(4): 519-524, doi: 10.4293/108680812X13462882736736, indexed in Pubmed: 23484557.

13. Goolab BD. Vaginal hysterectomy and relative merits over abdomina and laparoscopically assisted hysterectomy. Best Pract Res Clin Obstet Gynaecol. 2013; 27(3): 393-413, doi: 10.1016/j.bpobgyn.2013.01.003, indexed in Pubmed: 23602203.

14. Sculpher M. Cost effectiveness analysis of laparoscopic hysterectomy compared with standard hysterectomy: results from a randomised trial. BMJ. 2004; 328(7432): 134-0, doi: 10.1136/bmj.37942.601331.ee.

15. Augusto $\mathrm{KL}$, Brilhante $\mathrm{AV}$, Modesto GC, et al. Costs and mortality rates of surgical approaches to hysterectomy in Brazil. Rev Saude Publica. 2018; 52: 25, doi: 10.11606/S1518-8787.2018052000129, indexed in Pubmed: 29561962.

16. Boyd LR, Novetsky AP, Curtin JP. Effect of surgical volume on route of hysterectomy and short-term morbidity. Obstet Gynecol. 2010; 116(4): 909-915, doi: 10.1097/AOG.0b013e3181f395d9, indexed in Pubmed: 20859155.

17. Wright JD, Lewin SN, Deutsch I, et al. Effect of surgical volume on morbidity and mortality of abdominal hysterectomy for endometrial cancer. Obstet Gynecol. 2011; 117(5): 1051-1059, doi: 10.1097/AOG.0b013e31821647a0, indexed in Pubmed: 21508742.

18. Rogo-Gupta LJ, Lewin SN, Kim JH, et al. The effect of surgeon volume on outcomes and resource use for vaginal hysterectomy. Obstet Gynecol. 2010; 116(6): 1341-1347, doi: 10.1097/AOG.0b013e3181fca8c5, indexed in Pubmed: 21099600. 